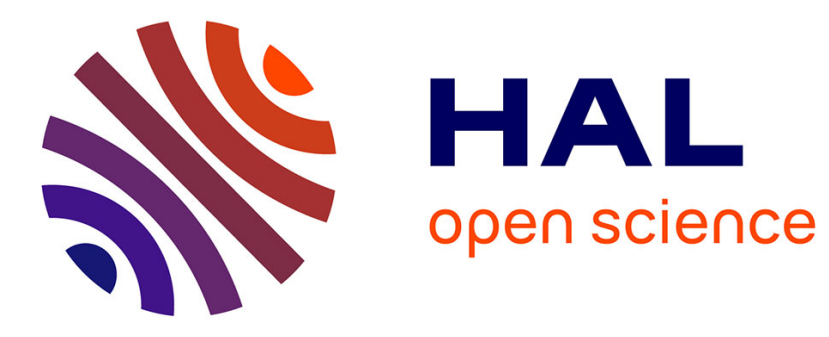

\title{
Evaluation of a Temporal Association between Vaccination and Subdural Hematoma in Infants
}

\author{
Juliette Fleury, Pauline Scherdel, Eric Frampas, Nathalie Vabres, Caroline \\ Rey-Salmon, Marie Blot, Elise Launay, Martin Chalumeau, Christèle Gras-Le
}

Guen

\section{To cite this version:}

Juliette Fleury, Pauline Scherdel, Eric Frampas, Nathalie Vabres, Caroline Rey-Salmon, et al.. Evaluation of a Temporal Association between Vaccination and Subdural Hematoma in Infants. The Journal of Pediatrics, 2019, 209, pp.134 - 138.e1. 10.1016/j.jpeds.2019.01.044 hal-03484697

\section{HAL Id: hal-03484697 \\ https://hal.science/hal-03484697}

Submitted on 20 Dec 2021

HAL is a multi-disciplinary open access archive for the deposit and dissemination of scientific research documents, whether they are published or not. The documents may come from teaching and research institutions in France or abroad, or from public or private research centers.
L'archive ouverte pluridisciplinaire HAL, est destinée au dépôt et à la diffusion de documents scientifiques de niveau recherche, publiés ou non, émanant des établissements d'enseignement et de recherche français ou étrangers, des laboratoires publics ou privés.

\section{(ㅇ)(1) $\$$}

Distributed under a Creative Commons Attribution - NonCommerciall 4.0 International 


\title{
Evaluation of a Temporal Association between Vaccination and Subdural Hematoma in Infants
}

\author{
Juliette Fleury, $\mathrm{MD}_{2}^{1,2}$ Pauline Scherdel, $\mathrm{PhD}_{2}^{2,3,4}$ Eric Frampas, $\mathrm{MD}, \mathrm{PhD}^{5}$, Nathalie Vabres, $\mathrm{MD}^{1,2}$, \\ Caroline Rey-Salmon, $\mathrm{MD}^{6}$, Marie Blot, $\mathrm{MD}^{2}$, Elise Launay, $\mathrm{MD}, \mathrm{PhD}^{2,3,4}$, Martin Chalumeau, $\mathrm{MD}, \mathrm{PhD}^{3,7 . \star 2}$, and \\ Christèle Gras-Le Guen, MD, PhD $2,3,4, \underline{\star}$
}

Objective To investigate a temporal association between vaccination and subdural hematoma, the main feature of abusive head trauma.

Study design From a prospective population-based survey carried out in 1 administrative district in France between January 2015 and April 2017, including all infants between 11 and 52 weeks old who underwent a first cerebral imaging (computerized tomography scan or magnetic resonance imaging), we conducted a nested case-control study. Vaccine exposure was compared between cases (infants with subdural hematoma) and 2-3 paired controls, without subdural hematoma or any other imaging findings compatible with abusive head trauma. Cases and controls were matched on chronological ( \pm 7 days) and gestational ( $\leq 33$ vs $>33$ weeks) ages, respectively. Vaccination status was collected in the personal national pediatric health booklet.

Results Among the 228 prospectively surveyed infants, 28 had subdural hematoma including 22 with abusive head trauma. The mean chronological age at imaging was 5.3 months among the 28 cases and the 62 controls, who did not differ significantly in median time since last vaccination (1.4 vs 1.3 months, $P=.62)$ or frequency of at least 1 vaccination since birth ( $86 \%$ vs $89 \%$; matched-pairs OR $0.77,95 \% \mathrm{Cl} 0.17-3.86)$ or within 7 days $(0.94,0.08-6.96), 14$ days $(0.70,0.12-2.92)$, or 21 days $(0.48,0.08-1.98)$ before cerebral imaging.

Conclusions We found no significant temporal association between vaccination and subdural hematoma diagnosis, which must continue to be considered a red flag for abusive head trauma and child abuse. ( $J$ Pediatr 2019; $\mathbf{\square}: 1-5)$.

busive head trauma, including various cerebral, cranial and/or spinal injuries that result from inflicted injury to infants and young children, is the most common cause of traumatic death in infants in developed countries. ${ }^{1,2}$ A mean of $45 \%$ of survivors have permanent neurologic sequelae, and many of these children develop long-term psychological sequelae. ${ }^{3-5}$ With no reference standard test for abusive head trauma and the exact mechanism of the injury often unknown without a confessing perpetrator, the diagnosis relies on a combination of clinical, social, biological, and radiological features. Retinal hemorrhage and central nervous system imaging findings are the cornerstones of the diagnosis of abusive head trauma. The main abusive head trauma imaging feature is subdural hematoma, ${ }^{2,6}$ which are often multiple and bilateral, located mainly in frontal, parietal, or temporal subdural spaces and/or the interhemispheric space and/or the posterior fossa. ${ }^{2,7-12}$ Other features of abusive head trauma include rupture and/or thrombosis of bridging veins and cerebral edema.

The diagnosis of child abuse has social, psychological, and legal implications that lead potential perpetrators under investigation and their lawyers to suggest alternative causal mechanisms, such as accidental head trauma with a trivial mechanism, hypoxia, or vitamin C deficiency. ${ }^{8,9,13-19}$ These alternative mechanisms have been refuted, ${ }^{20,21}$ but in a recent context of global vaccination skepticism, a new alternative causative mechanism for retinal hemorrhage and neuroradiological features suggestive of abusive head trauma has emerged: adverse reaction to vaccines. ${ }^{13,14}$ The publications that raised this hypothesis did not refer to any experimental or epidemiologic data. ${ }^{13,14}$ However, this hypothesis may induce confusion in courts and devastating effects by delaying child protection. ${ }^{21,22}$ Diagnostic delays of abusive head trauma expose infants to risk of re-injury by repeated trauma, associated with a demonstrated increase in morbidity and mortality. ${ }^{20}$

From the ${ }^{1}$ Unité d'accueil des enfants en danger; ${ }^{2}$ Pediatric and Emergency Department, University Hospital of Nantes, Nantes; ${ }^{3}$ Inserm, UMR1153 Epidemiology and Biostatistics Sorbonne Paris Cité Center (CRESS), Obstetrical, Perinatal, and Pediatric Epidemiology Research Team (EPOPé), Paris Descartes University, Paris; ${ }^{4}$ Epidémiologie Clinique, Centre d'Investigation Clinique (CICO04); ${ }^{5}$ Department of Radiology, University Hospital of Nantes, Nantes, France; ${ }^{6}$ Urgences médico-judiciaires, Hôpital HôtelDieu, AP-HP, Paris, France; and ${ }^{7}$ Department of Genera Pediatrics and Pediatric Infectious Diseases, Hôpital Necker-Enfants malades, AP-HP, Paris Descartes University, Paris, France

${ }^{*}$ Contributed equally.

C.G-L. was supported by the unrestricted educational grant "Prix Véronique Roualet 2018" and has received travel grants from GSK and Pfizer. E.L. has received travel grants from GSK. The funders had no role in the travel grants from GSK. The funders had no role in the study design, data collection and analysis, decision to publish, or preparation of the manuscript.
authors declare no conflicts of interest.

$\overline{0022-3476 / \$ \text { - see front matter. } \odot 2019 \text { Elsevier Inc. All rights reserved. }}$ https://doi.org/10.1016/.jpeds.2019.01.044 
Because of the vital importance of achieving appropriate child protection, the hypothesis of a temporal association between vaccination and retinal hemorrhage or neuroradiological features suggestive of abusive head trauma should be explored. Binenbaum et al refuted a temporal association between vaccination and retinal hemorrhage in a case-control study comparing 4 infants with retinal hemorrhage with 3421 controls, by using vaccination records. ${ }^{23}$ No similar investigation has examined such a temporal association between vaccination and subdural hematoma, which is the aim of the present study.

\section{Methods}

We conducted a case-control study nested in a prospective population-based survey. ${ }^{24}$ The protocol was approved by the ethics committee of the Nantes University Hospital (RC16_0175), allowing for this observational study with information for parents available only on billboards placed in all public places of the hospital. The message on billboards indicated that data collected for routine medical care could be reused for observational studies if parents did not express their opposition to this use. We used the Strengthening the Reporting of Observational Studies in Epidemiology (STROBE) guidelines to report this study (STROBE checklist; available at www.jpeds.com). ${ }^{25}$

All consecutive infants from 11 to 52 weeks old who underwent a first cerebral imaging such as computerized tomography (CT) scan or magnetic resonance imaging (MRI) in 1 administrative district in France, the LoireAtlantique area, between January 2015 and April 2017 were prospectively included. The exhaustiveness of inclusions was a posteriori assessed by identifying in the electronic registry of the department of radiology of the Nantes University Hospital all the infants with eligibility criteria. During the study period, this hospital was the only facility in the administrative district under study where such imaging was performed in infants. All cases of sudden unexpected infant death and suspected child abuse were also referred to this hospital during the study period, and these infants systematically underwent cerebral imaging. We a posteriori checked that no transfer from other regions occurred during the study period and that all included cases and controls were living in the Loire-Atlantique area.

\section{Nested Case-Control Design}

Among the cohort of infants from 11 to 52 weeks old who underwent a first cerebral imaging, cases were infants with subdural hematoma. The 11-week limit corresponds to the beginning of the national immunization program, which starts at 8 weeks of age, ${ }^{26}$ plus the length of the maximum window of exposure (see Statistical Analyses section). We limited the focus to subdural hematoma, which is a robust sign of abusive head trauma whether CT scan or MRI is used as cerebral imaging notably, when a bleeding disorder has been excluded, as in the present study (see below). ${ }^{2,10,11}$
Cerebral imaging was analyzed twice by experienced radiologists, first during routine care and second, for the purpose of this study, by the head of the department of radiology who was masked to vaccine exposure, routine care analysis results, and clinical context. Among children with 1 or more subdural hematoma, a final diagnosis of abusive head trauma was retained by the hospital child protection unit only after careful clinical, social, radiological and biological evaluation, as recommended. ${ }^{27}$

Within the surveyed cohort, each case was matched randomly to a maximum of 3 controls whose cerebral imaging did not show any neuroradiological features suggestive of abusive head trauma. Cases and controls were matched on chronological ( \pm 7 days) and gestational ( $\leq 33$ vs $>33$ weeks) ages. Cases and controls with hemophilia, thrombocytopenia, or other bleeding disorders were excluded.

\section{Vaccine Exposure}

Vaccination status was collected at the time of the neurologic imaging analysis by directly examining the national pediatric personal health booklet, carried by the parents. In France, these booklets are systematically completed at each vaccine injection and contain all the individual medical health information from birth. When the booklet was not available, the eligible child was excluded from the study (Figure). To define exposure, all vaccinations were considered: pentavalent (Diphtheria, Tetanus, acellular Pertussis, Polio and Haemophilus influenzae Type $b$ vaccine combination), hexavalent (Diphtheria, Tetanus, acellular Pertussis, Hepatitis B, Polio, and Haemophilus influenzae Type $b$ vaccine combination), pneumococcal conjugate, rotavirus, measles, mumps and rubella, bacillus Calmette-Guerin, or influenza vaccines.

\section{Statistical Analyses}

We compared vaccine exposure between cases and controls during 4 predefined exposure windows: since birth, and within 7,14 , and 21 days before cerebral imaging. These windows were selected based upon the study by Binenbaum et al. ${ }^{23}$ We used a conditional logistic regression model to calculate matched-pairs ORs and their 95\% CIs. Weighting was introduced because the matching process did not allow for finding the same number of controls for each case. This weighting resulted in an apparent discrepancy between the exact and weighted number of controls. All analyses involved use of SAS v 9.4 (SAS Institute, Cary, North Carolina).

\section{Results}

\section{Sample}

During the study period, among the 228 infants from 11 to 52 weeks old who underwent cerebral imaging (61 MRI and 167 CT scan), 28 had subdural hematoma, including 22 with abusive head trauma (Figure); 6 had a nonabusive head trauma cause of subdural hematoma: 2 had been 


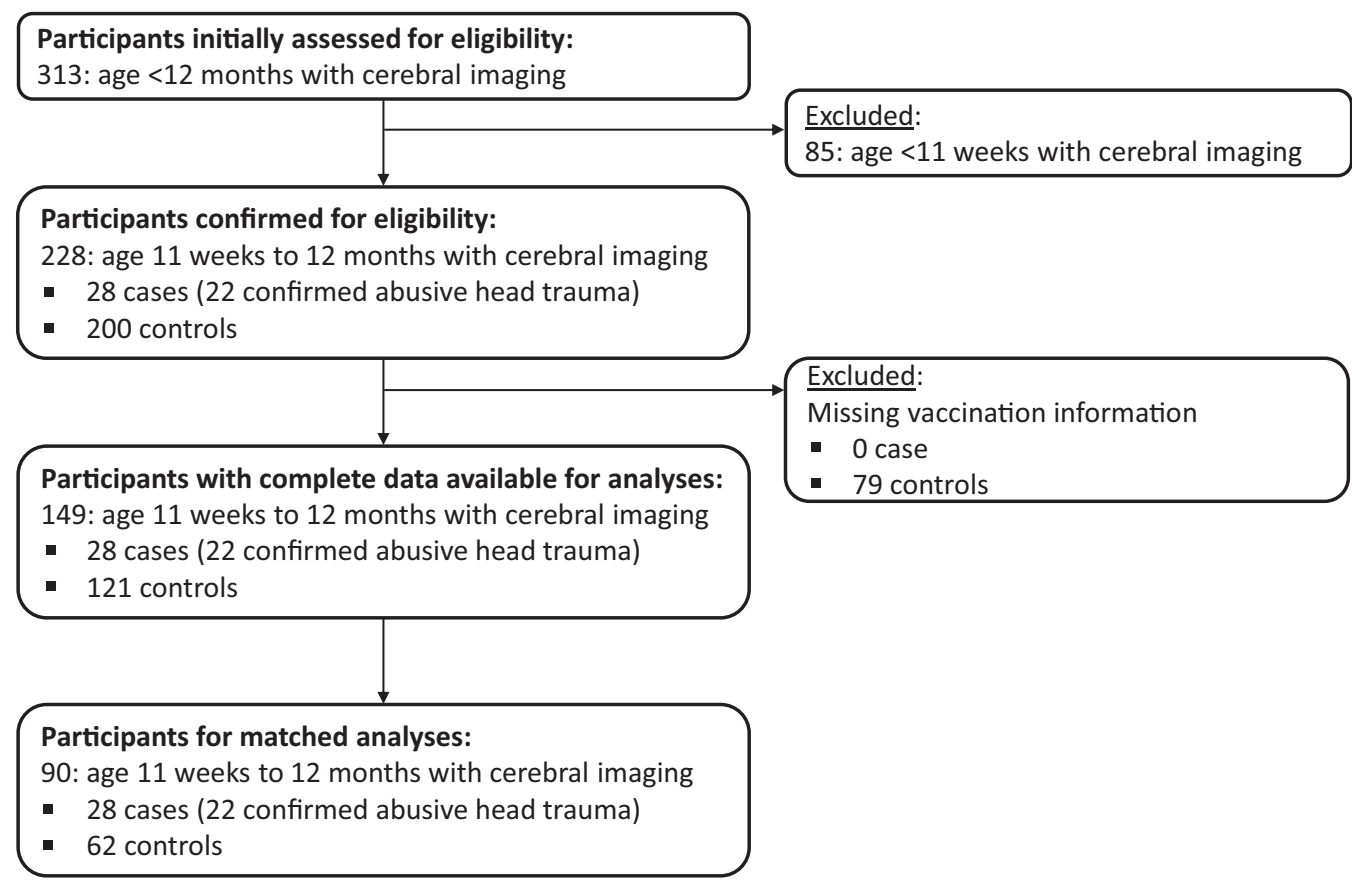

Figure. Flow of cases and controls in the study.

ejected from a vehicle after a high kinetic-energy crash and 4 had recently undergone extracorporeal circulation during surgery for a cardiac congenital malformation. Vaccination information was available for 28 of 28 (100\%) cases and 121 of $200(61 \%)$ controls. Controls without and with missing data did not differ significantly by sex, but controls without missing data were significantly younger (Table I; available at www.jpeds.com). Among the 149 cases and controls with available information on vaccination, 15 had not received any injection, 124 had received a hexavalent vaccine, 8 a pentavalent vaccine, 123 a pneumococcal vaccine, and 1 an influenza vaccine. We observed no vaccinations for rotavirus, measles, mumps and rubella, or bacillus Calmette-Guerin.

\section{Case-Control Analysis}

The matching process allowed for pairing 1, 2, and 3 controls for 7,8 , and 13 cases, respectively. Thus, analyses were based on data for 28 infants with subdural hematoma and 62 controls without any neuroradiological features suggestive of abusive head trauma (Table II). The mean (SD) chronological age at imaging was 5.3 (2.4) months (median [IQR]: 4.5 [3.4-6.5] for cases and 5.3 (2.7) (4.6 [3.4-6.5]) for controls $)(P=.78$, as expected by the matching process). All cases and controls were born at gestational age of $>33$ weeks.

Cases and controls did not differ significantly $(P>.50)$ in frequency of at least 1 vaccination since birth ( $86 \%$ vs $89 \%$; matched-pairs OR $0.77,95 \%$ CI $0.17-3.86)$, within the last 7 days ( $11 \%$ vs $11 \%$; $0.94,0.08-6.96), 14$ days ( $18 \%$ vs $22 \% ; 0.70,0.12-2.92)$, and 21 days (18\% vs $27 \% ; 0.48$,
0.08-1.98) before cerebral imaging. They did not differ in median time since the last vaccination $(P=.62): 1.4$ months ([IQR]: [1.0-1.9]; mean [SD]: $1.6[1.3]$ ) vs 1.3 months ([IQR]: [0.5-2.1]; mean [SD]: 1.8 [2.2]).

\section{Discussion}

In this study exploring a temporal association between vaccination and subdural hematoma among infants undergoing cerebral imaging, we did not observe any significant association in any of the prediagnosis exposure windows studied. We tested several windows of exposure because authors who previously suggested an association did not clearly describe the pathophysiological mechanism and the delays involved. ${ }^{23}$ Studying the short- and long post-vaccination periods seemed important to detect any potential adverse events. ${ }^{13}$ The lack of any temporal association constitutes a strong argument to support vaccination is not involved in the etiology of subdural hematoma.

The background context for the study was the recurrent alternative hypothesis of various possible mechanisms implicated in subdural hematoma diagnosis, specifically vaccine injection. ${ }^{13,28,29}$ This alternative hypothesis, which takes advantage of the general context of vaccine skepticism especially marked in France, is being used more and more frequently in legal procedures. ${ }^{30}$ There is no perfect design to refute such hypothesis. Given that subdural hematoma symptoms and signs can be discrete, such design needed to involve a systematic CT scan or MRI to avoid missing "silent" subdural hematoma. Given the stress and potential adverse 


\begin{tabular}{|c|c|c|c|c|}
\hline Mean $( \pm S D)$ median $[I Q R]$ unless otherwise stated & $\begin{array}{l}\text { Cases } \\
(n=28)\end{array}$ & $\begin{array}{c}\text { Controls }\left(n=62 ; n^{\prime}=84\right. \\
\text { after weighting) }\end{array}$ & $\begin{array}{l}\text { Matched-pairs } \\
\text { OR }[95 \% \mathrm{Cl}]\end{array}$ & $\boldsymbol{P}$ \\
\hline Sex, girls, $\mathrm{n}(\%)$ & $11(39.3)$ & $38(44.6)^{\dagger}$ & - & - \\
\hline Gestational aqe $\leq 33$ wk, $n(\%)$ & $0(0)$ & $0(0)^{\dagger}$ & Matching criteria & \\
\hline Chronological age at imaging (mo) & $5.3( \pm 2.4)$ & $5.3( \pm 2.7)^{\dagger}$ & Matching criteria & \\
\hline & $4.5[3.4-6.5]$ & $4.6[3.4-6.5]$ & & \\
\hline \multicolumn{5}{|l|}{ Vaccinations $\geq 1$} \\
\hline since birth, $\mathrm{n}(\%)$ & $24(85.7)$ & $75(89.3)^{\dagger}$ & $0.77[0.17-3.86]$ & .93 \\
\hline$<7$ d before cerebral imaging, $\mathrm{n}(\%)$ & $3(10.7)$ & $10(11.3)^{\dagger}$ & $0.94[0.08-6.96]$ & 1.00 \\
\hline$<14$ d before cerebral imaging, $\mathrm{n}(\%)$ & $5(17.9)$ & $19(22.0)^{\dagger}$ & $0.70[0.12-2.92]$ & .86 \\
\hline$<21$ d before cerebral imaging, $n(\%)$ & $5(17.9)$ & $23(26.8)^{\dagger}$ & $0.48[0.08-1.98]$ & .44 \\
\hline \multirow[t]{2}{*}{ Age of last vaccination (mo) } & $3.7( \pm 1.5)$ & $3.5( \pm 1.3)^{\dagger}$ & $\begin{array}{c}0.70[0.00] \\
-\end{array}$ & - \\
\hline & $4.0[2.3-4.3]$ & $4.0[2.4-4.2]$ & & \\
\hline \multirow[t]{2}{*}{ Time since last vaccination (mo) } & $1.6( \pm 1.3)$ & $1.8( \pm 2.2)^{\dagger}$ & - & - \\
\hline & $1.4[1.0-1.9]$ & $1.3[0.5-2.1]$ & & \\
\hline
\end{tabular}

*Weighting was introduced because the matching process did not allow for finding the same number of controls for each case. This weighting results in an apparent discrepancy between the exact $(n=62)$ and weighted $\left(n^{\prime}=84\right.$; ie, 28 cases $^{\star} 3$ ) number of controls.

tResults were weighted on the number of matched controls per case (see ${ }^{*}$ ).

effects related to CT or MRI procedures in infants, a prospective cohort of children exposed to vaccines would not have been ethical. Thus, the only relevant design was a case-control study of infants with a clinical indication for a cerebral CT scan or MRI. Because case-control studies are susceptible to selection bias, a population-based approach using a nested design within a cohort seemed the most appropriate. We focused on the presence of a subdural hematoma rather than the association of various neuroradiological features proposed in the literature as suggestive of abusive head trauma to avoid any foreseeable discussion and expert debate about abusive head trauma radiological signs. ${ }^{7,11}$ Indeed, subdural hematoma is considered the cornerstone of abusive head trauma diagnosis and is its most frequent feature. ${ }^{2,6}$ In addition to the negative results of Binenbaum et al, our results indicate that vaccination should join the long list of refuted alternative pseudoscientific pathophysiological hypotheses (hypoxia, $, 15,18,29,31$ vitamin $\mathrm{C}$ deficiency, ${ }^{13,32}$ or trivial mechanisms ${ }^{8,9,15}$ ) proposed as responsible for radiological features suggestive of abusive head trauma. Interestingly, in our study excluding infants with a bleeding disorder, the other sources of subdural hematoma were extremely severe traffic injury or having undergone recent extracorporeal circulation during cardiac surgery. ${ }^{31}$

Our study has several strengths. The neuroradiological images were re-interpreted by an experienced radiologist who was masked to the clinical context, the first routine care interpretation, and the vaccination status of infants to avoid differential classification bias. There was no discrepancy between the 2 radiological analyses. To avoid information bias, detailed vaccination information was not obtained from parental interview but instead was collected directly by the investigators from each health booklet, which is mandatorily completed at each vaccination in France. Finally, because the national vaccination program is initiated as soon as age 8 weeks, a potential cumulative effect of vaccines or an interaction between several vaccines would have been identified with our design.
Some limitations were present in our study. Despite our study being population-based, a small number of cases were recruited in relation to the low incidence of subdural hematoma. This small number of cases resulted in low statistical power to detect a very small association with vaccination. However, we did not detect any tendency for a possible association, but rather the opposite. The percentage of missing data was substantial among controls $(40 \%)$ but much lower than in the study by Binenbaum et al (57\%) probably because our study was prospective. Controls without missing data were significantly younger than controls without missing data but did not differ in sex ratio. The force and direction of the potential selection bias related to these missing data cannot be anticipated.

Overall, we found no significant temporal association between vaccination and subdural hematoma diagnosis in infants, whatever the prediagnosis exposure window studied. Thus, the notion of previous vaccination should not be considered a possible cause of subdural hematoma in infants. Subdural hematoma in infants must continue to be considered a red flag for abusive head trauma and child abuse. $^{8,9,15}$

We thank Dr Martine Balençon for her help, the Orrick, Herrington and Sutcliffe LLP group for the "Véronique Roualet" grant, and the clinical and research staff who contributed to the study.

Submitted for publication Jul 6, 2018; last revision received Jan 10, 2019; accepted Jan 24, 2019.

Reprint requests: Christèle Gras-Le Guen, MD, PhD, Pediatric and Emergency Department, University Hospital of Nantes, 38 Boulevard Jean Monnet, 44093 Nantes Cedex, France. E-mail: christele.grasleguen@chu-nantes.fr

\section{References}

1. Christian C, Block R, Committee on Child Abuse and Neglect. Abusive head trauma in infants and children. Pediatrics 2009;123:1409-11.

2. Duhaime A, Christian C, Rorke L, Zimmerman R. Nonaccidental head injury in infants-the "shaken-baby syndrome". N Engl J Med 1998;338:1822-9. 
3. Ewing-Cobbs L, Kramer L, Prasad M, Canales D, Louis P, Fletcher J, et al. Neuroimaging, physical, and developmental findings after inflicted and noninflicted traumatic brain injury in young children. Pediatrics 1998;102:300-7.

4. Afifi T. Child maltreatment in Canada: an understudied public health problem. Can J Public Health 2011;102:459-61.

5. Johnson S, Riley A, Granger D, Riis J. The science of early life toxic stress for pediatric practice and advocacy. Pediatrics 2013;131:319-27.

6. Kemp AM. Investigating subdural haemorrhage in infants. Arch Dis Child 2002;86:98-102.

7. Adamsbaum C, Morel B, Ducot B, Antoni G, Rey-Salmon C. Dating the abusive head trauma episode and perpetrator statements: key points for imaging. Pediatr Radiol 2014;44:S578-88.

8. Geddes J, Plunkett J. The evidence base for shaken baby syndrome. BMJ 2004;328:719-20.

9. Geddes J, Vowles G, Hackshaw A, Nickols C, Scott I, Whitwell H. Neuropathology of inflicted head injury in children. II. Microscopic brain injury in infants. Brain 2001;124:1299-306.

10. Hedlund G. Abusive head trauma: extra-axial hemorrhage and nonhemic collections. In: Kleinman P, ed. Diagnostic imaging of child abuse. $3^{\text {rd }}$ ed. Cambridge, United Kingdom: Cambridge University Press; 2015.

11. Adamsbaum C, Billette de Villemeur T, Husson B, Laurent Vannier A, Touré $\mathrm{H}$, Zerah $\mathrm{M}$. Non-accidental injuries of the brain and spinal cord. In: Rey-Salmon C, Adamsbaum C, eds. Abuse: diagnostic and forensic considerations. $1^{\text {st }}$ ed. Cham, Switzerland: Springer International Publishing; 2017

12. Section on Radiology, American Academy of Pediatrics. Diagnostic imaging of child abuse. Pediatrics 2009;123:1430-5.

13. Clemetson C. Elevated blood histamine caused by vaccinations and vitamin $\mathrm{C}$ deficiency may mimic the shaken baby syndrome. Med Hypotheses 2004;62:533-6.

14. Innis M. Vaccines, apparent life-threatening events, Barlow's disease, and questions about shaken baby syndrome. J Am Phys Surg 2006;11: 17-9.

15. Geddes J, Hackshaw A, Vowles G, Nickols C, Whitwell H. Neuropathology of inflicted head injury in children. I. Patterns of brain damage. Brain 2001;124:1290-8.

16. Chadwick D. A witnessed short fall mimicking presumed shaken baby syndrome (inflicted childhood neurotrauma). Pediatr Neurosurg 2008;44:517.
17. Williams A, Sunderland R. Neonatal shaken baby syndrome: an aetiological view from Down Under. Arch Dis Child Fetal Neonatal Ed 2002;87:F29-30.

18. Galaznik J. A response to mimics of child abuse: can choking explain abusive head trauma? J Forensic Leg Med 2016;39:46-9.

19. Squier W. Shaken baby syndrome: the quest for evidence. Dev Med Child Neurol 2008;50:10-4.

20. Jenny C, Hymel K, Ritzen A, Reinert S, Hay T. Analysis of missed cases of abusive head trauma. JAMA 1999;281:621-6.

21. Choudhary AK, Servaes S, Slovis TL, Palusci VJ, Hedlund GL, Narang SK, et al. Consensus statement on abusive head trauma in infants and young children. Pediatr Radiol 2018;48:1048-65.

22. Narang S, Estrada C, Greenberg S, Lindberg D. Acceptance of shaken baby syndrome and abusive head trauma as medical diagnoses. J Pediatr 2016;177:273-8.

23. Binenbaum G, Christian C, Guttmann K, Huang J, Ying G, Forbes B. Evaluation of temporal association between vaccinations and retinal hemorrhage in children. JAMA Ophthalmol 2015;133:1261-5.

24. Ernster VL. Nested case-control studies. Prev Med 1994;23:587-90.

25. von Elm E, Altman DG, Egger M, Pocock SJ, Gotzsche PC, Vandenbroucke JP, et al. The Strengthening the Reporting of Observational Studies in Epidemiology (STROBE) statement: guidelines for reporting observational studies. Lancet 2007;370:1453-7.

26. Ministère des Solidarités et de la Santé. Calendrier des vaccinations et recommandtions vaccinales 2018. Paris: Direction générale de la Santé; 2018. p. 72.

27. Piteau S, Ward M, Barrowman N, Plint A. Clinical and radiographic characteristics associated with abusive and nonabusive head trauma: a systematic review. Pediatrics 2012;130:315-23.

28. Gardner H. Immunizations, retinal and subdural hemorrhages: are they related? Med Hypotheses 2005;64:663.

29. Squier W. The "Shaken Baby" syndrome: pathology and mechanisms. Acta Neuropathol 2011;122:519-42.

30. Larson HJ, de Figueiredo A, Xiahong Z, Schulz WS, Verger P, Johnston IG, et al. The state of vaccine confidence 2016: global insights through a 67-country survey. EBioMedicine 2016;12:295-301.

31. Feldman KW, Bethel R, Shugerman RP, Grossman DC, Grady MS, Ellenbogen RG. The cause of infant and toddler subdural hemorrhage: a prospective study. Pediatrics 2001;108:636-46.

32. Fung E, Nelson E. Could vitamin C deficiency have a role in shaken baby syndrome? Pediatr Int 2004;46:753-5. 
Table I. Comparison of controls with and without vaccination injection information

Mean ( $\pm \mathrm{SD})$, median [IQR] unless With vaccination injection information

Without vaccination injection

otherwise stated

$(n=121)$

information $(\mathbf{n}=\mathbf{7 9})$

Sex, girls, $n(\%)$

$40.5(49)$

$5.8( \pm 2.6)$

$5.1[3.5-7.8]$

$46.8(37)$

$7.0( \pm 2.9)$

$6.3[4.9-9.1]$ 